\title{
Effects of thalassemia minor plus iron deficiency anemia on weight, height, and body mass index
}

\author{
Mehmet Rami Helvaci (1) \\ Yusuf Aydin (1) \\ Abdulrazak Abyad (3) \\ Lesley Pocock (4) \\ (1) Specialist of Internal Medicine, MD \\ (2) Middle-East Academy for Medicine of Aging, MD \\ (3) medi+WORLD International
}

Corresponding author:

Prof Dr Mehmet Rami Helvaci,

ALANYA, Antalya, Turkey

Phone: 00-90-506-4708759

Email: mramihelvaci@hotmail.com

Received September 2020. Accepted October 2020. Published November 1, 2020.

Please cite this article as: Helvaci MR et al. Effects of thalassemia minor plus iron deficiency anemia on weight, height, and body mass index. Middle East J Intern Med 2020; 13(2): 29-33. DOI: 10.5742/MEJIM2020.93787

\section{ABSTRACT}

Background: We tried to understand possible effects of thalassemia minor (TM) plus iron deficiency anemia (IDA) on weight, height, and body mass index (BMI).

Material and methods: Cases with TM plus IDA with a hematocrit (Hct) value of lower than $30 \%$ were collected into the first, and age and sex-matched controls with a Hct value of $30 \%$ and greater were collected into the second group.

Results: The study included 89 patients (65 females) with TM plus IDA in the first, and 195 controls (143 females) in the second group, respectively. Their mean ages and female ratios were 35.7 versus 35.3 years and $73.0 \%$ versus $73.3 \%$, respectively $(p>0.05$ for both). Mean Hct and mean corpuscular volume values were $23.2 \%$ versus $37.6 \%$ and 60.0 versus 81.1 $\mathrm{fL}$, respectively ( $p=0.000$ for both). Weight (63.3 versus $70.9 \mathrm{~kg}, \mathrm{p}=\mathbf{0 . 0 0 0})$, height $(161.2$ versus $165.2 \mathrm{~cm}$, p=0.001), BMI (24.4 versus $25.9 \mathrm{~kg} / \mathrm{m} 2$, p=0.007), diastolic blood pressure (BP) (78.9 versus $86.8 \mathrm{mmHg}$, $\mathrm{p}=0.000)$, and smoking $(8.9 \%$ versus $22.5 \%, p<0.01)$ were all lower in the first group, significantly.
Conclusion: Although the well known suppressor effects of smoking on appetite and the lower prevalence of smoking in the first group, TM plus IDA have significant suppressor effects on weight, height, and BMI. In this field, TM and IDA must be researched separately to be able to understand the effects of low Hct values and/or iron deficiency with increased number of cases. Similarly, effects of higher BMI and smoking on BP must be researched separately with further studies, too.

Key words: Thalassemia minor, iron deficiency anemia, weight, height, body mass index, diastolic blood pressure, metabolic syndrome 


\section{Introduction}

Weight, height, and body mass index (BMI) are probably under the effects of various hereditary and environmental factors. Many studies assume that genes are important in them, and there is a common agreement that parents' weight and height affect the statures of the children $(1,2)$. External factors may also play roles on weight, height, and BMI. It was shown in the previous study that rural and urban living conditions may cause up to a $30 \%$ of difference in weight and a $12 \%$ difference in height (3). But there is still little known about genetic and environmental control of weight, height, and BMI. On the other hand, anemia is defined as a reduction of hemoglobin in red blood cells (RBC) and millions of people suffer from it. Iron deficiency anemia (IDA) and alpha and/or beta thalassemia minor (TM) are the most common causes of anemia in the world. Hemoglobin is the iron-rich protein of $\mathrm{RBC}$ that carries oxygen from lungs into the body. The final consequence is a decrease in the blood's ability to carry oxygen into the body, and supply it with the energy that it needs. So the important body processes including cell building, tissue repair, and muscular activity slow down in case of TM and IDA. Dizziness and a decrease in mental acuity may develop due to the lack of oxygen into the brain, and heart failure due to the increased work of the heart. Loss of appetite, palpitation, difficulty in concentration, depression, fatigue, coldness of extremities, pallor (reduced amount of oxyhemoglobin in the skin and mucous membranes), brittle nails, cessation of menstruation, breathlessness on exertion, glossitis (inflammation of the tongue), and angular cheilitis (inflammation of mouth corners) are the other common symptoms and signs seen with TM and/ or IDA. All of the above symptoms and signs are related to the decreased cell turnover and increased work of heart due either to the decreased oxygen supply or to the decreased iron supplement of tissues. We tried to understand possible effects of TM plus IDA on weight, height, and BMI in the present study.

\section{Material and Methods}

The study was performed in the Internal Medicine Units of the Dumlupinar and Mustafa Kemal Universities on routine check up patients between August 2007 and July 2016. The medical history of all cases including already used medications was learnt, and a routine check up procedure including fasting plasma glucose, creatinine, hepatic function tests, markers of hepatitis viruses $\mathrm{A}, \mathrm{B}, \mathrm{C}$ and human immunodeficiency virus, a posterior-anterior chest $\mathrm{X}$-ray film, and an electrocardiogram were performed for all cases. Current daily smokers with six pack-months and cases with a past of three pack-years were accepted as smokers. Due to the very low prevalence of alcoholism in Turkey (4), we did not include regular alcohol intake into the study. Systolic and diastolic blood pressure (BP) were checked with a mercury sphygmomanometer after a five-minute rest in seated position in the office. Insulin using diabetics and patients with devastating illnesses including malignancies, chronic renal diseases, cirrhosis, hyper- or hypothyroidism, heart failure, thalassemia intermedia and major, sickle cell diseases (SCD), and autoimmune hemolytic anemias were excluded to avoid their possible effects on the weight, height, BMI, and hematocrit (Hct) values. Body weight and height was measured, and the BMI was calculated by the same physicians instead of verbal expressions, since there is evidence that heavier individuals systematically underreport their weight relatively to the lighter ones (5). Weight in kilograms is divided by height in meters squared (6). IDA was diagnosed with serum iron, iron binding capacity, and ferritin. TM were diagnosed with hemoglobin electrophoresis performed via high performance liquid chromatography after the iron replacement therapy in cases with the IDA. Eventually, patients with TM plus IDA with a Hct level of lower than $30 \%$ were collected into the first, and age and sex-matched controls with a Hct level of $30 \%$ and greater were collected into the second groups, and compared in between. Mann-Whitney $U$ test, Independent-Samples $T$ test, and comparison of proportions were used as the methods of statistical analyses.

\section{Results}

The study included 89 patients (65 females) with TM plus IDA in the first and 195 controls (143 females) in the second group, respectively. Their mean age and female ratio were 35.7 versus 35.3 years and $73.0 \%$ versus $73.3 \%$, respectively ( $p>0.05$ for both). Mean Hct and mean corpuscular volume values were $23.2 \%$ versus $37.6 \%$ and 60.0 versus $81.1 \mathrm{fL}$, respectively $(\mathrm{p}=0.000$ for both). Weight (63.3 versus $70.9 \mathrm{~kg}, \mathrm{p}=0.000)$, height (161.2 versus $165.2 \mathrm{~cm}, \mathrm{p}=0.001)$, BMI (24.4 versus $25.9 \mathrm{~kg} / \mathrm{m} 2, \mathrm{p}=0.007)$, diastolic BP (78.9 versus $86.8 \mathrm{mmHg}$, $\mathrm{p}=0.000)$, and smoking $(8.9 \%$ versus $22.5 \%, \mathrm{p}<0.01)$ were all lower in the first group, significantly (Table 1 - next page).

\section{Discussion}

IDA is the most common cause of anemia in the world, and mostly seen in children and women at the reproductive period due to the increased iron requirement in growth, menstruation, pregnancy, and lactation. For example, around $10 \%$ of adolescent girls and women in childbearing age have iron deficiency, compared with less than $1 \%$ of young men in the United States (7). These ratios are probably much higher in the underdeveloped and developing countries of the world. The female predominance $(73.0 \%)$ and young mean age of the TM plus IDA patients (35.7 years) of the present study is probably due to menorrhagia since IDA can be caused by insufficent dietary intake of iron, insufficient absorption of iron, or blood loss which is often caused by menstruation. IDA induced symptoms and signs may be due to the tissue hypoxia and/or iron deficiency since iron takes vital roles in the various tissues and enzymes of the body. Glossitis, angular cheilitis, koilonychia (spoon-shaped nails), and dysphagia due to formation of esophageal webs in the Plummer-Vinson syndrome may be some of the indicators of various roles of iron other than the hemoglobin alone in the body. Thus moderate anemia induced retarded weight, height, and BMI in the present study may also be due to the various roles of iron in tissues and enzymes other than the hemoglobin alone. TM are the other most common causes of microcytic anemia in the world, particularly in the Mediterranean region. They are autosomal recessively inherited disorders. Normal hemoglobin is composed of two pairs of alpha and beta globin chains. Alpha thalassemias result in a decreased alpha globin synthesis, causing an excess of beta chains in adults. The excess beta chains form unstable tetramers (called hemoglobin $\mathrm{H}$ ) which have abnormal oxygen 
Table 1: Characteristic features of the study cases

\begin{tabular}{|c|c|c|c|}
\hline Variables & $\begin{array}{c}\text { Hematocrit values } \\
<30 \%\end{array}$ & $p$-value & Hematocrit values $\geq 30 \%$ \\
\hline Number & 89 & & 195 \\
\hline Age (year) & $35.7 \pm 13.8(15-75)$ & Ns* & $35.3 \pm 11.4(13-79)$ \\
\hline Female ratio & $73.0 \%(65)$ & Ns & $73.3 \%(143)$ \\
\hline Hematocrit value $(\%)$ & $23.2 \pm 3.9(14-29)$ & $\underline{0.000}$ & $\underline{37.6 \pm 4.2(30-53)}$ \\
\hline$M C V+$ value $(f L)$ & $\underline{60.0 \pm 8.6(45-97)}$ & $\underline{0.000}$ & $\underline{81.1 \pm 7.1(58-93)}$ \\
\hline Weight (kq) & $\underline{63.3 \pm 16.8(37-119)}$ & $\underline{0.000}$ & $\underline{70.9 \pm 15.4(41-114)}$ \\
\hline Height $(\mathrm{cm})$ & $\underline{161.2 \pm 8.3(145-180)}$ & $\underline{0.001}$ & $\underline{165.2 \pm 8.8(147-189)}$ \\
\hline$\underline{B M I} \neq(\mathrm{kq} / \mathrm{m} 2)$ & $\underline{24.4 \pm 6.9(15.0-47.5)}$ & $\underline{0.007}$ & $25.9 \pm 5.5(17.8-42.0)$ \\
\hline$\underline{\text { Smoking }}$ & $\underline{8.9 \%(8)}$ & $\leq 0.01$ & $\underline{22.5 \%(44)}$ \\
\hline Systolic BP§ ( $\mathrm{mmHg})$ & $127.3 \pm 19.8(80-190)$ & Ns & $124.1 \pm 21.3(90-200)$ \\
\hline Diastolic BP $(\mathrm{mmHq})$ & $\underline{78.9 \pm 11.6(60-110)}$ & $\underline{0.000}$ & $\underline{86.8 \pm 11.5(60-130)}$ \\
\hline
\end{tabular}

*Non-significant $(\mathrm{p}>0.05) \quad \uparrow$ Mean corpuscular volume $\$$ Body mass index $\S$ Blood pressure

dissociation curves. Whereas in beta thalassemia, excess alpha chains bind to the RBC membranes causing membrane damage, and they form toxic aggregates at high concentrations. Generally, TM are prevalent in populations that evolved in humid climates where malaria is endemic since thalassemias protect these people from malaria due to the easy degradation of the RBC. Alpha and beta TM are also frequent in Turkey, particularly in the Mediterranean region. Pathophysiologic mechanisms of the significantly lower weight, height, and BMI of the TM plus IDA patients may include low Hct values induced tissue hypoxia, increased cardiac, bone marrow, and splenic activities, and some vital roles of iron in enzymes and tissues of the body. In this field, IDA and TM patients must be researched separately with increased number of cases in further studies. But it is obvious that neither the IDA nor the alpha and/or beta TM do not shorten lifespan of the human being, instead they may prolong the lifespan with some suppressor effects on weight and BMI in the metabolic syndrome.

Normally the weight, height, and BMI may be determined by a complex network of hormonal, nutritional, physical, and genetic factors. For example, around 70 genes may take a role in the regulation of bone mass (8), and some genes were shown to affect both the BMI and bone geometric parameters (9). The same results were also shown in animals where the results indicate substantial additive genetic control of Brahman body weight to hip height ratio (10). Leptin is a hormone produced mainly by adipocytes, and it acts chiefly to control the body weight (11). Leptin is also expressed on osteoblasts, and acts as a skeletal growth factor and promotes bone mineralization $(12,13)$. The pleiotropic effect of leptin on the BMI and bone geometry may also be supported by the evidence of genetic correlation of leptin with the BMI and bone geometry (14). Whereas, the body length growth velocity was found not to be affected by genes in some studies (15). On the other hand, we detected in the present study that weight, height, and BMI were significantly retarded in the TM plus IDA patients $(p<0.05$ for all). Whereas, in the previous study performed on 122 patients (58 females) with the SCD with a mean age of 28.6 years, although the BMI and weight were significantly retarded in the SCD cases (24.9 versus $20.7 \mathrm{~kg} / \mathrm{m} 2$ and 71.6 versus $57.8 \mathrm{~kg}$, respectively, $\mathrm{p}=0.000$ for both) probably due to the accelerated vascular endothelial damaging process initiated at birth, the heights were similar in the SCD and control cases (166.1 versus $168.5 \mathrm{~cm}$, respectively, $\mathrm{p}>0.05$ ) probably due to its hereditary nature chiefly (16).

Chronic endothelial damage may be the major cause of aging by inducing disseminated tissue hypoxia all over the body. Some of the well-known accelerator factors of the inflammatory process are physical inactivity, sedentary lifestyle, excess weight, smoking, alcohol, chronic inflammation, prolonged infections, and cancers for the development of irreversible consequences including obesity, hypertension (HT), diabetes 
mellitus (DM), cirrhosis, peripheric artery disease (PAD), chronic obstructive pulmonary disease (COPD), chronic renal disease (CRD), coronary heart disease (CHD), mesenteric ischemia, osteoporosis, and stroke, all of which terminate with early aging and premature death. They were researched under the titles of metabolic syndrome, aging syndrome, and accelerated endothelial damage syndrome in the literature, extensively (17-19). The syndrome may be the most common type of vasculitis all over the world. Much higher BP of the afferent vasculature may be the major underlying cause by inducing recurrent injuries on endothelium. Thus the term of venosclerosis is not as famous as atherosclerosis in the literature. Secondary to the chronic endothelial damage, inflammation, edema, and fibrosis, vascular walls become thickened, their lumens are narrowed, and they lose their elastic nature which reduces blood flow and increases systolic BP further. Although early withdrawal of causative factors may prevent final consequences, after development of obesity, HT, DM, cirrhosis, PAD, COPD, CRD, CHD, mesenteric ischemia, osteoporosis, or stroke, endothelial changes cannot be reversed completely due to their fibrotic nature $(20,21)$. Other chronic inflammatory processes including SCD, rheumatologic disorders, prolonged infections, and cancers may accelerate the process. Finally it is not a surprise that the metabolic syndrome terminates with a shortened survival in human beings (22).

Alcohol and smoking cause a chronic inflammatory process on the vascular endothelium depending on the concentrations of their products in the blood. So both of them can cause an accelerated atherosclerosis, end-organ insufficiency, early aging, and premature death. Thus both of them should be included among the major components of the metabolic syndrome. Atherosclerotic effects of smoking are the most obvious in Buerger's disease. It is an obliterative vasculitis characterized by inflammatory changes in the small and medium-sized arteries and veins, and it has never been reported in the absence of smoking in the literature. On the other hand, smoking in human beings and nicotine administration in animals may be associated with a decreased BMI value. Nicotine supplied by patch after smoking cessation decreased caloric intake in a dose-related manner (23). According to an animal study, nicotine lengthens intermeal time and decreases amount of meal eaten (24). Additionally, the mean BMI seems to be the highest in the former, the lowest in the current, and medium in the never smokers (25). Smoking may be associated with a postcessation weight gain (26). Similarly, although CHD was detected with similar prevalences in both genders, prevalence of smoking and COPD were higher in males against the higher BMI, low density lipoproteins, triglycerides, white coat hypertension, HT, and DM in females (27). Similarly, the prevalence of myocardial infarction is increased six-fold in women and three-fold in men who smoke 20 cigarettes per day (28). In another definition, smoking is more dangerous for women due to the associated excess weight and its consequences in them. So smoking is probably a powerful atherosclerotic risk factor with some suppressor effects on appetite (29). Smoking-induced weight loss may be related to the smoking-induced chronic vascular endothelial inflammation all over the body since loss of appetite is one of the major symptoms of disseminated inflammation all over the body. Physicians can even understand healing of their patients by means of their normalizing appetite. Several toxic substances found in the cigarette smoke get into the circulation by means of the respiratory tract, and cause a vascular endothelial inflammation up to the clearance from the circulation. But due to the repeated smoking habit, the clearance process never terminates. So the patients become ill with loss of appetite, permanently. In another explanation, smoking-induced weight loss is an indicator of being ill instead of being healthy. After smoking cessation, appetite comes back with a prominent weight gain but the returned weight is their physiological weight, actually. Despite the well known suppressor effects of smoking on appetite and the lower prevalence of smoking in the first group, weight was significantly lower in the TM plus IDA group in the present study.

As a conclusion, although the well known suppressor effects of smoking on appetite and the lower prevalence of smoking in the TM plus IDA group, TM plus IDA have significant suppressor effects on weight, height, and BMI. In this field, TM and IDA must be researched separately to be able to understand the effects of low Hct values and/or iron deficiency with increased number of cases. Similarly, effects of higher BMI and smoking on the BP must be researched separately with further studies, too.

\section{References}

1. Rona RJ, Chinn S. Genetic and environmental influences on growth. J Med Screen 1995; 2(3): 133-139.

2. Preece MA. The genetic contribution to stature. Horm Res 1996; 45(2): 56-58.

3. Habicht JP, Martorell R, Yarbrough C, Malina RM, Klein RE. Height and weight standards for preschool children. How relevant are ethnic differences in growth potential? Lancet 1974; 1(7858): 611-614.

4. Helvaci MR, Yaprak M, Abyad A, Pocock L. Atherosclerotic background of hepatosteatosis in sickle cell diseases. World Family Med 2018; 16(3): 12-18.

5. Bowman RL, DeLucia JL. Accuracy of self-reported weight: a meta-analysis. Behav Ther 1992; 23: 637-635.

6. Third Report of the National Cholesterol Education Program (NCEP) Expert Panel on Detection, Evaluation, and Treatment of High Blood Cholesterol in Adults (Adult Treatment Panel III) final report. Circulation 2002; 106(25): 3143-3421.

7. Looker AC, Dallman PR, Carroll MD, Gunter EW, Johnson CL. Prevalence of iron deficiency in the United States. JAMA 1997; 277(12): 973-976.

8. Khoury MJ. Genetic epidemiology and the future of disease prevention and public health. Epidemiol Rev 1997; 19(1): 175 180.

9. Xu H, Xiong DH, Xu FH, Zhang YY, Lei SF, Deng HW. Association between VDR Apal polymorphism and hip bone mineral density can be modified by body mass index: a study on postmenopausal Chinese women. Acta Biochim Biophys Sin (Shanghai) 2005; 37(1): 61-67.

10. Riley DG, Coleman SW, Chase CC Jr, Oslon TA, Hammond AC. Genetic parameters of body weight, hip height, and the ratio of weight to hip height from random regression analyses of Brahman feedlot cattle. J Anim Sci 2007; 85(1): 42-52. 
11. Considine RV, Sinha MK, Heiman ML, Kriauciunas A, Stephens TW, Nyce MR, et al. Serum immunoreactive-leptin concentrations in normal-weight and obese humans. New Engl J Med 1996; 334(5): 292-295.

12. Reseland JE, Syversen U, Bakke I, Qvigstad G, Eide LG, Hjertner $\mathrm{O}$, et al. Leptin is expressed in and secreted from primary cultures of human osteoblasts and promotes bone mineralization. J Bone Miner Res 2001; 16(8): 1426-1433.

13. Ducy P, Amling M, Takeda S, Priemel M, Schilling AF, Beil FT, et al. Leptin inhibits bone formation through a hypothalamic relay: a central control of bone mass. Cell 2000; 100(2): 197-207.

14. Livshits G, Pantsulaia I, Trofimov S, Kobyliansky E. Genetic variation of circulating leptin is involved in genetic variation of hand bone size and geometry. Osteoporosis Int 2003; 14(6): 476-483.

15. Livshits G, Peter I, Vainder M, Hauspie R. Genetic analysis of growth curve parameters of body weight, height and head circumference. Ann Hum Biol 2000; 27(3): 299-312.

16. Helvaci MR, Kaya H. Effect of sickle cell diseases on height and weight. Pak J Med Sci 2011; 27(2): 361-364.

17. Eckel RH, Grundy SM, Zimmet PZ. The metabolic syndrome. Lancet 2005; 365(9468): 1415-1428.

18. Helvaci MR, Kaya H, Sevinc A, Camci C. Body weight and white coat hypertension. Pak J Med Sci 2009; 25(6): 916-921.

19. Helvaci MR, Ayyildiz O, Muftuoglu OE, Yaprak M, Abyad A, Pocock L. Aging syndrome. World Family Med 2017; 15: $39-42$.

20. Helvaci MR, Aydin LY, Aydin Y. Digital clubbing may be an indicator of systemic atherosclerosis even at microvascular level. HealthMED 2012; 6(12): 3977-3981.

21. Helvaci MR, Seyhanli M. What a high prevalence of white coat hypertension in society! Intern Med 2006; 45(10): 671674.

22. Helvaci MR, Kaya H, Seyhanli M, Cosar E. White coat hypertension is associated with a greater all-cause mortality. $\mathrm{J}$ Health Sci 2007; 53(2): 156-160.

23. Hughes JR, Hatsukami DK. Effects of three doses of transdermal nicotine on post-cessation eating, hunger and weight. J Subst Abuse 1997; 9: 151-159.

24. Miyata G, Meguid MM, Varma M, Fetissov SO, Kim HJ. Nicotine alters the usual reciprocity between meal size and meal number in female rat. Physiol Behav 2001; 74(1-2): 169 176.

25. Laaksonen M, Rahkonen O, Prattala R. Smoking status and relative weight by educational level in Finland, 1978-1995. Prev Med 1998; 27(3): 431-437.

26. Froom P, Melamed S, Benbassat J. Smoking cessation and weight gain. J Fam Pract 1998; 46(6): 460-464.

27. Helvaci MR, Kaya H, Gundogdu M. Gender differences in coronary heart disease in Turkey. Pak J Med Sci 2012; 28(1): 40-44.

28. Prescott E, Hippe M, Schnohr P, Hein HO, Vestbo J. Smoking and risk of myocardial infarction in women and men: longitudinal population study. BMJ 1998; 316(7137): 1043-1047.
29. Helvaci MR, Aydin Y, Gundogdu M. Atherosclerotic effects of smoking and excess weight. J Obes Wt Loss Ther 2012; 2: 145 . 